\title{
Endoscopic Treatment of Gastric Adenoma with Argon Plasma Coagulation
}

\author{
Kee Myung Lee and Jin Hong Kim \\ Ajou University School of Medicine, \\ Korea
}

\section{Introduction}

The term gastric adenoma means a benign lesion of the glandular epithelium having variable degrees of cellular atypia and showing papillary or tubular structures. Because long-term follow-up studies of gastric adenomas reveal malignant transformations, it is well known they are premalignant. Since these lesions lie histologically and clinically on the borderline of between whether they are benign or malignant, it is extremely important for clinicians to determine whether they are to be treated or not (Morson, 1980; Kamiya, 1982; Rugge, 1994).

For a long time, there was no specific treatment policy of gastric adenomas and treatment varied from close endoscopic follow-ups to endoscopic resection, considering its heterogeneous clinical consequences (Di Gregorio, 1993; Saraga, 1987). When gastric epithelial dysplasia is classified using the two or three tier system, each group shows a different clinical course. For gastric adenoma with high grade dysplasia (HGD), endoscopic resection has become the standard treatment because of risk of malignant progression and synchronous carcinomas (Lansdown, 1990; Farinati, 1993). Many western publications have recommended close endoscopic follow-up of patients with moderate/low grade gastric epithelial dysplasia (Rugge, 1991, Fertitta, 1993; Rugge, 1991). The frequency of the followup has been recommended to be every three to 12 months at least during the first year, but it is still unknown of how long the follow-up should be maintained for when no progression has been detected (Bearzi, 1994; Fertitta, 1993). The disadvantages of endoscopic follow-ups are patient anxiety, risk of disease progression, and low patient compliance for an undefined period (Lansdown, 1990; Rugge, 1991). Though endoscopic resection has become frequently applied for gastric adenoma with low grade dysplasia (LGD), there is ongoing controversy considering its relatively benign natural course and clinical significance. Although endoscopic resection is a less invasive procedure than surgical resection, it still carries the risk of complications and requires hospitalization of several days (Ono 2001, O'Mahony, 2001; Miyata 2000).

Argon plasma coagulation (APC) is a kind of non-contact technique for tissue coagulation, which transfers high-frequency electric current through ionized argon gas to targeted lesions (Grund, 1994; Grunde, 1997). Because APC has an advantage of confining the thermal effect to the superficial layer of the gastrointestinal wall, APC has been used for the treatment of bleeding ulcers, hemorrhagic telangiectasias, and tumors (Chau, 2003; 
Cipolletta, 1998; Iacopini, 2007). For the treatment of early gastric cancer, APC has been used on a limited number of patients due to it being impossible to get a pathologic evaluation and to predict the depth of invasion (Sagawa, 2003; Kitamura, 2006). Considering that gastric adenomas are confined to the mucosa and the thermal effect of APC is extended to both the mucosa and submucosa, theoretically the gastric adenoma lesion can be eradicated with APC. APC has the advantage of preventing excessive tissue damage and perforation, due to the coagulation damage of tissue increasing the electrical impedance, in turn decreasing the electrical current and automatically stopping irradiation (Goulet Watson, 2000; Morson, 1980). Based on the above characteristics of $\mathrm{APC}$, it can most probably be the safer and most effective therapeutic option of treating gastric adenomas. However, it has been reported that some endoscopists have experienced an unexpected extension of tissue destruction and even perforation, which could have been due to host and technical factors. Therefore, APC has been proven not to be completely free from the risk of perforation (Hoyer, 1998; Prost, 2004). In this chapter, we will give a brief introduction about the APC procedure after the submucosal saline injection for the treatment of gastric adenomas at the out-patient clinic without any need for hospitalization.

\section{Gastric adenoma and its natural course}

Most adenomas present a pale surface, and few cases reveal redness on the surface. The frequency of gastric adenomas in different age groups reveals a tendency to increase markedly with aging, especially above the fifth decade. This tendency may have some relation to atrophic changes and especially intestinal metaplasia of the gastric mucosa among the aged (Morson, 1980; Kamiya, 1982; Rugge,1994). In some report, co-existent gastric carcinomas were more frequently found $(8 \%)$ in the same stomach and meticulous endoscopic evaluation was required. Epidemiological and histopathological studies have shown that intestinal type gastric cancers frequently develop through a sequence of histological events: namely diffuse chronic gastritis, often mucosal atrophy, intestinal metaplasia (complete and/or incomplete), gastric adenoma, and finally invasive carcinoma (Rugge, 1994; Saraga, 1987). Several prospective and retrospective serological studies have now linked Helicobacter pylori infection to gastric cancer (Talley, 1991; Parsonnet, 1991; Nomura, 1991). Helicobacter pylori infection is clearly associated with the induction of chronic inflammation of the gastric mucosa and the progressive development of metaplastic changes (Asaka, 2006).

Gastric adenoma is known to be a precancerous lesion of intestinal type adenocarcinoma and has diverse outcomes depending on the degree of dysplasia. According to the histological abnormality, gastric dysplasia has been graded using a two or three tier systemhigh/low or high/moderate/low grade dysplasia. Gastric adenoma with HGD was known to regress in about $5 \%$, to persist in $14 \%$, and to progress in $81-85 \%$ of cases (Miyata, 2000; Giovannini 1993). In chronological studies of malignant progression, the time period between diagnosis of HGD and gastric cancer varied and was between less than 1 month to 39 months (Farinati, 1993; Fertitta, 1993). It is suggested the possibility that some of these lesions already contained carcinomatous lesions but the invasive element was not included in the original biopsy sample (Lansdown, 1990; Farinati 1993). Endoscopic resection methods such as endoscopic mucosal resection (EMR) or endoscopic submucosal dissection 
(ESD) confirmed this possibility (Miyata, 2000; Giovannini, 1999; Watanabe, 2006). Therefore, gastric adenomas with HGD have to be treated as if it were an early gastric cancer, because of the risk of synchronous carcinoma and high risk of malignant progression (Farinati, 1993; Rugge, 1991).

Gastric adenomas with LGD show a different natural course. Gastric adenomas with LGD have been reported to regress in $38-49 \%$, to be persistent in $19-28 \%$, to progress in $5-21 \%$, and eventually to be diagnosed as gastric adenocarcinoma in 0-5\% of cases (Fertitta, 1993; Rugge, 1991). Although many cases of gastric adenomas with LGD do not progress, a number of cases were reported to have done so, progressing to HGD or carcinoma after a median follow-up period ranging from 34.5 to 41.5 months (Fertitta, 1993; Rugge, 1991). This long interval time suggests that gastric adenomas with LGD rarely contain carcinoma at the time of diagnosis (Fertitta, 1993; Rugge, 1991).

Many western publications recommended close endoscopic follow-up of gastric adenomas with LGD, every 3-12 months until no progression is detected (Bearzi, 1994; Fertitta 1993). However, this approach has many problems; patient anxiety, risk of disease progression, and low compliance with frequent and expensive follow-up for an undefined period. Provided that HGD has been confirmed with endoscopic biopsy, many authors suggest surgical or endoscopic resection. Endoscopic resection can offer a non-surgical solution for intramucosal adenocarcinoma with advances in endoscopic localization method (chromoscopy, NBI) and staging techniques (endoscopic ultrasound)(Ono, 2001; O'Mahony, 2001).

\section{Endoscopic resection of gastric adenoma}

Endoscopic resection methods such as EMR and ESD are already recognized as standard treatments of premalignant lesions and small intramucosal cancerous lesions (Giovannini, 1999; Watanabe, 2006; Takenaka, 2008). Because a lesion is resected by means of electrocautery snaring using the EMR method, EMR is typically used for removal of lesions smaller than $2 \mathrm{~cm}$ or piecemeal removal of larger lesions. ESD has been developed for en bloc removal of large lesions (usually more than $2 \mathrm{~cm}$ ) (Ono, 2001; O'Mahony, 2001). Using the ESD method, a circumferential mucosal incision and submucosal dissection is done with specialized endoscopic electrocautery knives after marking the lesion and then injecting saline into the submucosal layer (Oka, 2006; Takeuchi, 2007, Oka, 2006).

Although EMR and ESD are less invasive procedures than surgical operations, they still carry some risk of complications such as bleeding and perforation, and require hospital admission for a few days (Oka 2006; Takeuchi, 2007). ESD requires the use of expensive specialized knives and a longer procedure time, and runs a higher risk of bleeding or perforation, as compared to EMR (Ono, 2001). Considering the risk of synchronous carcinoma and malignant progression, endoscopic resection is the best therapeutic option of gastric adenomas with HGD (Lansdown, 1990; Farinati, 1993). However, because gastric adenomas with LGD have a relatively benign natural course, endoscopic resection might be an excessive and expensive procedure (Rugge, 1995; Fertitta, 1993). From this point of view, the treatment of gastric adenomas with LGD should be different from the therapeutic option for gastric adenomas with HGD or intramucosal adenocarcinoma. In gastric adenomas with LGD, it can be recommended that therapeutic modalities between the frequent endoscopic follow-up and endoscopic resection be done, because a number of cases were reported to have progressed. 


\section{Argon plasma coagulation}

Argon plasma coagulation (APC) is a non-contact technique for tissue coagulation in which a high-frequency electrical current is transferred to the target tissue by means of ionized argon gas. An APC applicator for endoscopic use was developed in 1994, making it possible to provide tangential irradiation to coagulate a target lesion uniformly (Grund, 1994). APC has been introduced to treat a broad range of gastrointestinal problems, including bleeding ulcers (Chau, 2003; Cipolletta, 1998), Dieulafoy's lesions (Iacopini, 2007), hemorrhagic telangiectasias (Olmos, 2006; Sato, 2005; Rolachon, 2000; Kwan, 2006; Nakamura, 2001), radiation proctitis (Kaassis, 2000; Postgate, 2007) and tumors (Sagawa, 2003; Kitamura, 2006). As the lesion becomes coagulated with APC irradiation, tissue electrical impedance sharply increases and electrical current abruptly decreases and is automatically transferred to surrounding tissue sites with low impedance (Grund 1994; Grund, 1997; Wahab, 1997). Therefore, APC irradiation can safely coagulate large areas of tissue within a short time and the excessive tissue damage can automatically be prevented (Wahab, 1997). This characteristic of APC confines the thermal effect to the superficial portion and is an advantage over conventional endoscopic cauterization. Therefore, APC seems to be the most popular non-contact technique for tissue coagulation in the gastrointestinal field.

\section{Argon plasma coagulation and early gastric cancer}

As economic development and medical advancement lengthen the life expectancy rate, the number of elderly patients with early gastric cancers who have a serious morbidity of being physically unable to withstand either surgical or endoscopic resection is increasing. Local ethanol injection (Imaoka, 1987), microwave coagulation (Tabuse, 1985), Nd:YAG laser treatment (Yasuda, 1993; Hiki, 1989; Sibille, 1995), and photodynamic therapy(Nakamura, 1990; Ell, 1998; Mimura, 1996) have been applied in such cases. Nd:YAG laser treatment is widely used in treating patients with gastric cancers as a curative or palliative therapy but has the drawback of being impossible of being tangentially irradiated (Tajiri, 1991; Hiki, 1989).

Sagawa et al (Sagawa, 2003) performed ex vivo experiments with swine gastric mucosal tissue in order to set the irradiation conditions of APC for the treatment of early gastric cancers based on histological analysis (Fig. 1). Under all output settings tested from 20 to $100 \mathrm{~W}$, the coagulation front became deeper as the duration of irradiation was prolonged, reaching a plateau after irradiation for 15 seconds with each power setting (Fig. 2). The ex vivo experiment demonstrated that the depth of coagulation could easily be adjusted by changing the irradiation time and current output. They recommended that irradiation at $60 \mathrm{~W}$ for 15 seconds $(900 \mathrm{~J} / \mathrm{cm} 2)$ is the ideal setting for intramucosal cancer because this setting could cauterize the whole mucosal layer but would not affect the deep submucosal layer. However, there is a concern that the effect of APC observed in the ex vivo experiment would be somehow attenuated in vivo because there is blood flow that may act as a heat sink in living tissue. In addition, there was a concern of chronological changes of coagulation depth within a few days after APC irradiation. They applied the APC technique for the treatment of 27 patients with intramucosal gastric cancers who had no lymph node metastases (T1N0M0). APC showed a very high efficacy (no recurrence in 26/27 patients) after a follow-up period of 18-49 months (median 30 months). High treatment efficacy was obtained in 12 of the 27 patients whose cancers 
were located at difficult locations for the endoscope to access, the cardia or posterior wall of the gastric body, probably by virtue of tangential irradiation and uniform cauterization over a wide area. With regard to complications, some patients experienced a sense of abdominal fullness and it was easily alleviated by endoscopic suction during the procedure.

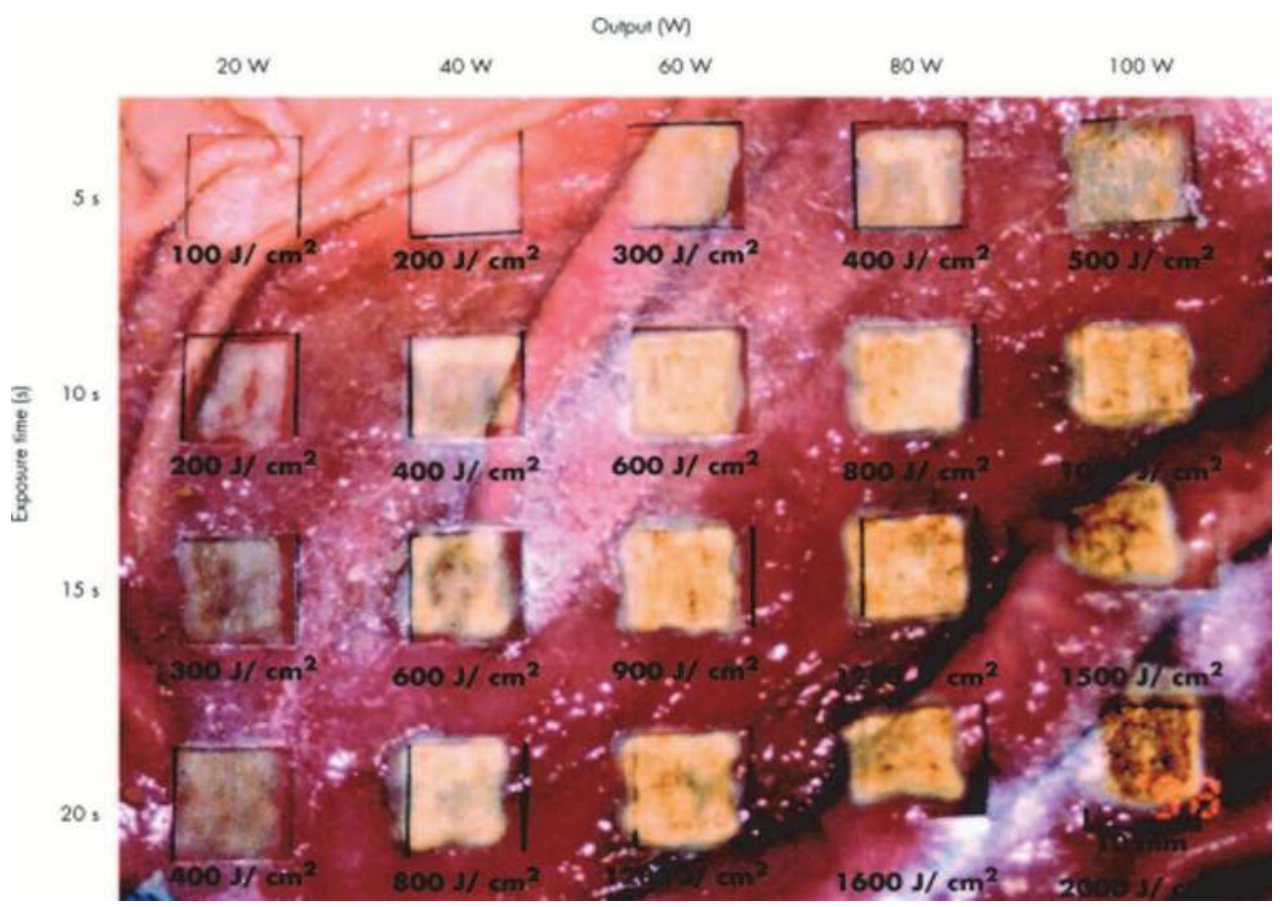

Fig. 1. Macroscopic findings of swine gastric mucosa irradiated by argon plasma coagulation (APC) under various conditions. The effect of APC was macroscopically studied on swine gastric samples at 20,40,60, 80, and $100 \mathrm{~W}$, with pulse durations of 5, 10, 15, and 20 seconds. The mucosa exposed to a greater output power of high frequency current and/or for a longer pulse duration underwent a more conspicuous color change from white to brown. (Quotation from Gut 2003;52:334-339 Sagawa T et al)

Kitamura et al (Kitamura , 2006) applied APC for the treatment of early gastric cancers in 40 patients who could not withstand surgical operation and endoscopic resection. There was no residual cancer or recurrence in 35 patients with intramucosal cancer after either a single session or multiple sessions of APC. In contrast, 3 patients $(60 \%)$, who had large tumors and were treated with a single session of APC, had residual cancers or recurrence among the 5 patients with submucosal cancers after APC treatment. All residual cancers were eradicated after retreatment with additional APC. They also suggested that small early gastric cancers could be successfully treated with only a single session of APC, while large protruding-type tumors or submucosal cancers required two sessions of APC. 

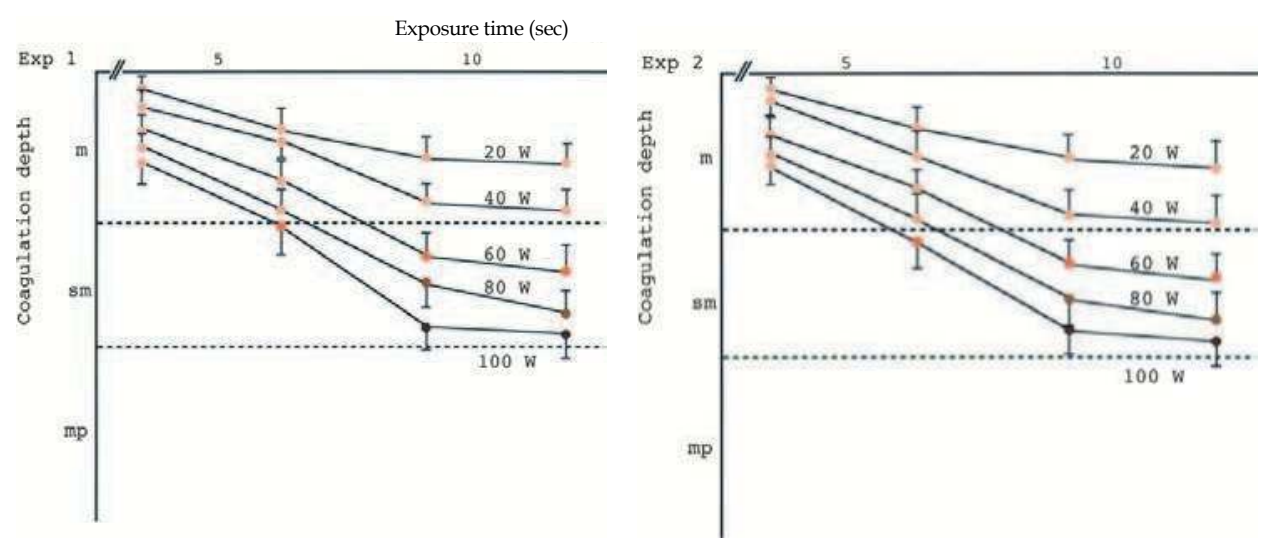

Fig. 2. Coagulation depth under various irradiation conditions based on histological analysis. The experiment was repeated twice using stomach specimens from two separate swine (Exp 1 and Exp 2). The coagulation front became deeper as the duration of irradiation was prolonged, reaching a plateau after irradiation for 15 seconds with each power setting. It was determined that the optimum treatment conditions of APC for clinical studies was a current of $60 \mathrm{~W}$ and a maximum irradiation time of $15 \mathrm{~s} / \mathrm{cm}^{2}$, which would not be expected to cause perforation. (Quotation from Gut 2003;52:334-339 Sagawa T et al)

\section{Argon plasma coagulation and gastric adenoma}

Although APC has been proven to be efficient for the treatment of mucosal and even submucosal cancers, it was only applied to the limited patients who were not suitable for surgical resection or EMR/ESD, because of drawbacks of APC including the inability to be histologically evaluated for the response to treatment immediately after the procedure, because it is impossible for a pathological specimen to be obtained with APC treatment (Sagawa, 2003; Kitamura, 2006). Therefore, either surgical or endoscopic resection is usually preferred to APC treatment for patients whose physical condition is tolerable.

The biologic behavior of adenomas is quite different from that of carcinomas. Because adenomas are limited and confined to the mucosal layer, gastric adenomas with LGD have no capacity to invade or infiltrate into deeper layers of the gastric wall (Di Gregorio, 1993; Saraga, 1987). As APC at optimal setting can totally cauterize the mucosal layer and superficial portion of submucosal layer, theoretically gastric adenomas can be clearly eradicated with APC. Different from gastric adenomas with HGD which should be treated as an early gastric cancer because of the risk of synchronous carcinoma and high risk of malignant progression, gastric adenomas with LGD rarely contain carcinomatous lesions at the time of diagnosis (Farinati, 1993; Fertitta, 1993). Based on these characteristics, APC treatment has many merits over endoscopic resection and frequent endoscopic follow-up; short procedure time, low risk of bleeding and perforation, low procedure cost, and no requirement of hospitalization. Therefore, it could be a reasonable treatment of gastric adenomas with LGD.

APC treatment is characterized by non-contact coagulation, making it possible to provide tangential irradiation to coagulate a target site uniformly (Wahab, 1997; Wahab, 1997, Chau, 2003). This feature is an advantage over other endoscopic cauterization such as local ethanol 
injection, Nd:YAG laser treatment, photodynamic therapy, and microwave coagulation (Tajiri, 1991; Ell, 1998). APC treatment method of gastric adenomas is similar to that of early gastric cancers. After a circumferential area around the lesion is marked with sufficient distance, irradiation is performed in the manner at 60-90 W for 15 seconds $(900-1200 \mathrm{~J} / \mathrm{cm} 2)$, which makes the mucosa surface dry and the tissue to change from white to brown. Different from early gastric cancers in which one or two sessions of cauterization is usually required for eradication, one session of APC irradiation is sufficient for gastric adenomas because the depth of the lesion is limited. Inaccurate identification of boundary and the insufficient distance from the lesion to marking may be a more important factor of residual tumor after APC of gastric adenomas, as opposed to early gastric cancers.

\section{Argon plasma coagulation and thermal injury}

The thermal injury of APC is known to be confined to the mucosa and superficial submucosa layer and APC can theoretically prevent perforation. However, Kitamura et al (Kitamura, 2006) reported one case of perforation in 40 patients whose early gastric cancers were treated with APC. Fujishiro et al (Fujishiro, 2006; Fujishiro, 2008) investigated thermal tissue damage on the stomach of living minipigs to confirm the safety of APC, including a follow-up case. A minipig was sacrificed without delay after APC application, and a stomach specimen revealed that tissue damage was limited to the shallower submucosal layer regardless of the applied time (Fig. 1 and 2). The other was sacrificed after a one week follow-up, and its stomach specimen showed that granulomatous and fibrotic changes existed in the submucosal layer of the artificial ulcers at the pulse durations of 5 seconds and 10 seconds. However, APC with pulse duration of 20 seconds created the deep ulceration with destruction of the proper muscle layer when examined after one week, which was not detected in the minipig sacrificed soon after APC application (Fig. 3).

The thermal effects of APC have been studied in vitro with resected specimens of the stomach and other organs. Such models are limited to being evaluated to its biologic and healing response to thermal injury and the influence of digestive juices. Exposure of tissue directly to high temperatures causes an inflammatory response, coagulation necrosis, followed by desquamative necrosis. Immediately after exposure to thermal injury, histologic examinations of tissue specimens appeared normal, but necrosis occurred secondarily after formation of a nonvital layer (Fujishiro, 2006; Fujishiro, 2008). The electrical resistance of resected specimens is basically similar to that of the gastric mucosa in vivo. APC was reported to have tissue reaction of shrinkage, desiccation, coagulation, and devitalization from the applied surface to deep portion in order. Histological investigation may not detect the zone of devitalization, which means that tissue damage may be underestimated after APC treatment. APC is not completely safe from the risk of perforation, than we previously thought. This result suggests that we have to be aware of the risk of late perforation, which may occur a few days to a few weeks after APC application.

\section{Argon plasma coagulation and submucosal saline injection}

Previous experimental studies showed that thermal injury induced by APC was confined to the superficial area and deep tissue destruction caused by perforation was rare (Sagawa, 2003; Watson, 2000). Clinical experiences with endoscopic evaluation also supported the rarity of perforation and safety of APC treatment. However, there is still the possibility of 
the severe complication of perforation caused by APC as published in some reports (Yoshida, 2005; Fujishiro, 2008). And some studies indicated that APC-induced tissue damage could be extended to the proper muscle layer, which might lead to stricture or deformity of the gastrointestinal tract and also functional disturbance of the sphincter and peristaltic movement.
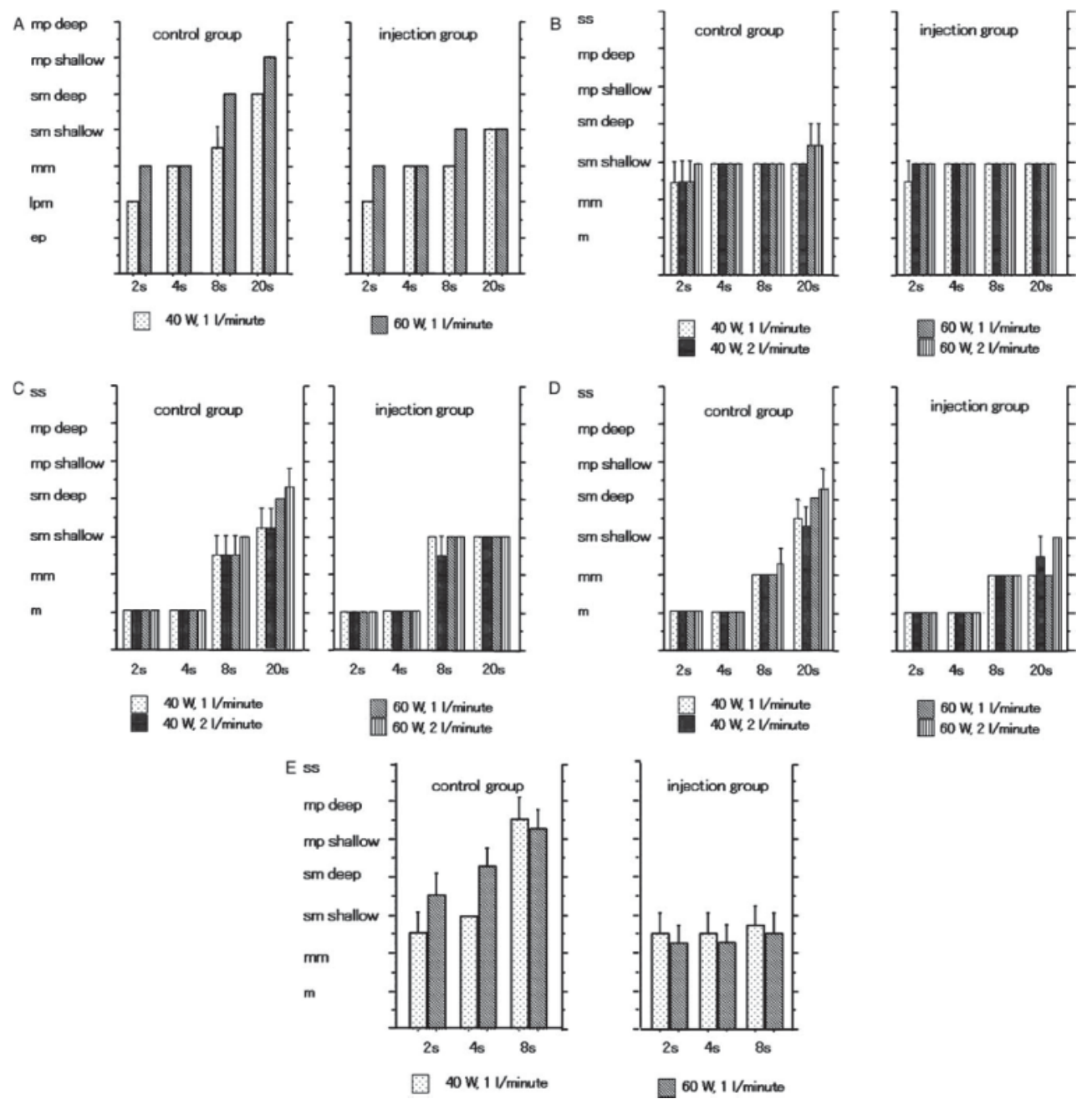

Fig. 3. Correlation between the depth of tissue damage and pulse duration.

The mean depth of the 4 observations is indicated as bars with a standard deviation in each condition. ${ }^{*} \mathrm{~m}$, the mucosal layer; ep, the epithelial layer; lpm, the lamina propria mucosae layer; $\mathrm{mm}$, the muscularis mucosae layer; sm, the submucosal layer; mp, proper muscle layer. A, Esophagus. B, Gastric upper third. C, Gastric middle third. D, Gastric lower third. E, Colon. (Quotation from Surg Laparosc Endosc Percutan Tech. 2006;16:307-11. Fujishiro et al) 
Because the risk of deep tissue injury cannot be predicted, meticulous setting of electrical current, flow rate of argon gas, and irradiation duration need to be carefully monitored for a successful APC treatment, taking into consideration anatomical characteristics and patient condition. Differences in the extent of tissue damage due to APC may originate mainly from differences in the wall thickness and in the proportions of the wall components. In an experimental study using porcine tissue, the deepest tissue damage was observed in the colon after APC irradiation at the same setting conditions, probably because the colonic wall is much thinner than that of the other organs. From the parts of the stomach, the deepest tissue damage was observed in the upper third of the stomach at a 2-second pulse duration, which may also be because of the thinness of the mucosal wall (Fujishiro, 2006; Fujishiro, 2008).

Submucosal injection of normal saline is an essential step for polypectomy and EMR for the prevention of bleeding and perforation (Fujishiro, 2004; Yoshida, 2005). The efficacy of submucosal injection of normal saline for the protection from thermal injury during APC was evaluated with animal studies (Norton, 2002; Fujishiro, 2006; Fujishiro, 2008). A minipig was sacrificed immediately after APC application, and its stomach specimen revealed that tissue damage deepened more as the applied time increased, but stayed confined to the mucosa and submucosa whether or not submucosal saline injections were done. The difference of depth of tissue injury was subtle between the two animal models, and the efficacy of submucosal saline injection was inconclusive in the immediate histopathologic evaluation of the specimen (Fujishiro, 2006; Fujishiro, 2008) (Fig. 4). An animal sacrificed one week after APC treatment revealed chronic inflammatory and fibrotic changes in the submucosal layer of the artificial ulcers and no injury of the proper muscle layer regardless of submucosal injection in the case of 5 and 10 seconds of irradiation time. APC irradiation without submucosal saline injections of a longer duration of 20 seconds only deepened the ulceration into the deep proper muscle layer. However, thermal injury after APC treatment of 20 seconds did not extend to the proper muscle layer in the animal with submucosal saline injection (Fig. 5). Therefore, submucosal saline injections are more likely to prevent the occasional deep tissue injury and the significant complication of perforation after long time irradiation of APC (Fujishiro, 2006; Fujishiro, 2008).

The reason of this discrepancy of tissue damage with and without follow-up may be the limitations of histology to evaluate thermal damage, especially the devitalization zone. Histological investigations may not be able to detect the zone of devitalization immediately after tissue damage with APC and it can underestimate the range of damage than the true one. These results have two important clinical meanings. First, there is a risk of deep tissue destruction after APC treatment and follow-up studies are needed to evaluate the damaged lesion. Second, submucosal injection of normal saline before APC may be useful to decrease deep tissue destruction and to prevent perforation in a living body. Other studies using a resected stomach specimen showed the usefulness of submucosal injection before APC. The study of Fujishiro et al (Fujishiro, 2006; Fujishiro, 2008) using a living minipig showed that APC irradiation after submucosal injection can limit thermal injury and prevent perforation not only immediately after procedure but also during the follow-up period.

In practice, some endoscopists' experienced an unexpected extension of tissue destruction and even perforation, which may be affected by various factors; host factors (mucosal and submucosa thickness, blood flow, inflammation, etc), technical factors (the extension of 
the gastric wall by inflated air, the irradiation angle, the distance between an applicator and tissue, irradiation duration, etc) (Postgate, 2007; Sagawa, 2003). Therefore, submucosal injection of normal saline may be the effective and practical method to prevent extensive damage to the proper muscle layer at any encountered situation.

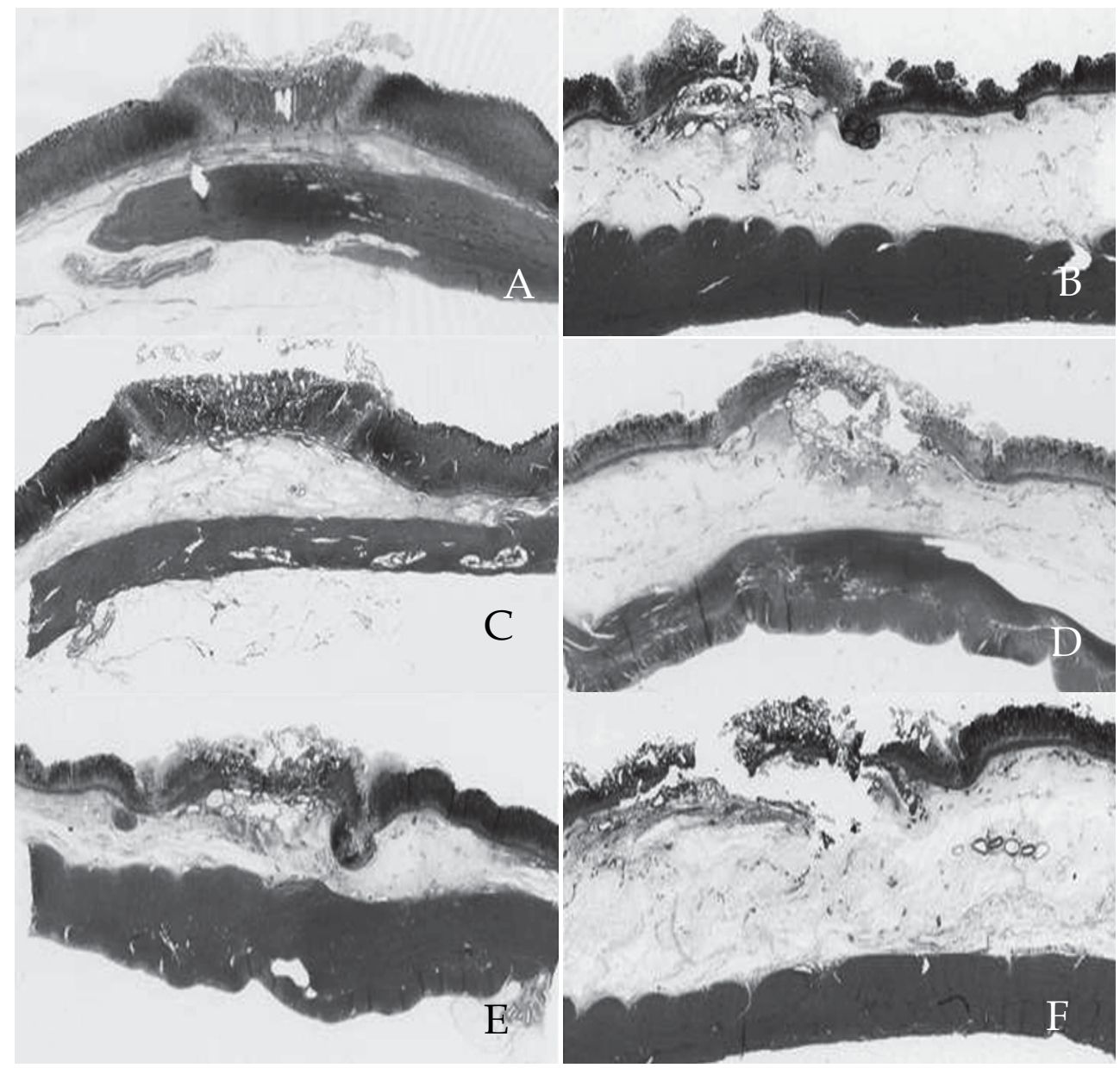

Fig. 4. Tissue injury in a minipig sacrificed immediately after APC. A) APC (5 seconds) without prior submucosal injection. B) APC (5 seconds) after submucosal injection. C) APC (10 seconds) without prior submucosal injection. D) APC (10 seconds) after submucosal injection. E) APC (20 seconds) without prior submucosal injection. F) APC (20 seconds) after submucosal injection. Tissue coagulation was limited to the deeper submucosal layer under all the conditions. The thermal effects tended to deepen with a longer pulse duration and no prior saline injection. With prior saline injection, the increased thickness of the submucosal layer might prevent injury to the deeper submucosal layer. (Quotation from Gut Liver. 2008;2:95-8. Fujishiro $\mathrm{M}$ et al) 
Since tissue damage up to the submucosal layer is considered sufficient for the treatment of gastric adenoma and intramucosal carcinoma, submucosal injections of saline has a high possibility of becoming the standard preparation prior to APC application in humans.

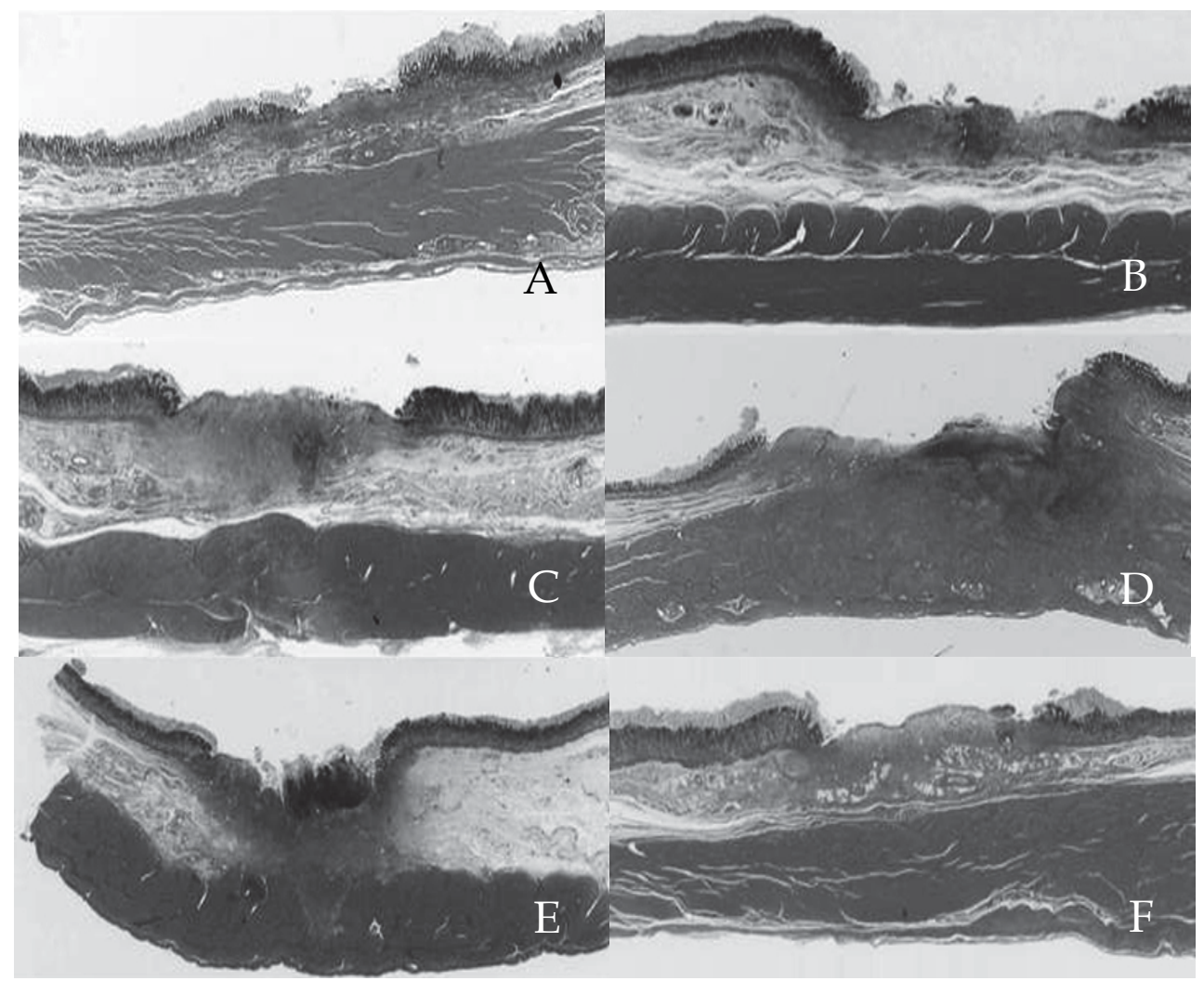

Fig. 5. Tissue damage in a minipig sacrificed 1 week after APC. A) APC (5 seconds) without prior submucosal injection. B) APC (5 seconds) after submucosal injection. C) APC (10 seconds) without prior submucosal injection. D) APC (10 seconds) after submucosal injection. E) APC (20 seconds) without prior submucosal injection.

F) APC (20 seconds) after submucosal injection. Under all the conditions except for 20 seconds of APC without prior submucosal injection, granulomatous and fibrotic changes were evident in the submucosal layer of the artificial ulcer, although the actual muscle layer appeared intact. Deep ulceration that destroyed the muscle layer was evident for 20 seconds of APC without submucosal injection.

(Quotation from Gut Liver. 2008;2:95-8. Fujishiro M et al)

\section{Gastric adenoma treatment with APC and submucosal saline injection}

Gastric adenoma is a precursor lesion of gastric cancer and is usually classified using a two-grade system, divided into LGD and HGD (Lansdown, 1990, Farinati, 1993). Gastric 
adenoma with HGD has a significant risk of disease progression and containing cancerous lesions, and it should be removed using an endoscopic resection procedure (Lansdown, 1990, Farinati, 1993). Although endoscopic resection is a less invasive procedure than surgical resection, it carries the risk of various complications and requires hospitalization of several days (Watanabe, 2006; Fujishiro, 2004, Yoshida, 2005). Gastric adenoma with LGD is a less progressive disease than HGD; nevertheless, it carries some risk of disease progression (Rugge, 1995; Fertitta, 1993). The risk factors of developing gastric adenoma are chronic atrophic gastritis, intestinal metaplasia, Helicobacter pylori infection, old age, cigarette smoking, and alcohol drinking (Talley, 1991; Parsonnet, 1991; Nomura, 1991). These risk factors induce irreversible mucosal changes and can provide an environment for gastric tumors to occur at multiple sites (Talley, 1991; Parsonnet, 1991; Nomura, 1991). Patients at risk also have an increased chance of developing metachronous lesions, and a meticulous endoscopic follow-up should be done after treatment of gastric adenoma. Considering the less progressive nature of gastric adenomas with LGD, new less invasive and feasible treatment methods as opposed to endoscopic resection are needed, because it has a higher risk of procedure-related complications, need for hospitalization and high medical expenses.

Gastric adenomas are confined to the mucosa of the gastric wall but are also located in reach of thermal effect of APC (Morson, 1980; Kamiya, 1982). Although APC is known to be an effective and safe procedure for early gastric cancers, bleeding control, and eradication of vascular lesions, they carry some risk of perforation due to the deep thermal effect. Based on the results of the animal study of Fujishiro et al (Fujishiro, 2006; Fujishiro, 2008), we have opted to use APC with submucosal saline injections (APC-SSI) to treat gastric adenomas with LGD. We have included submucosal saline injections as part of the routine procedure of APC for raising the mucosa and prevention of bleeding and perforation. It can be applied prior to APC to form an insulating fluid cushion in the submucosal layer to limit the thermal effect within the mucosa and superficial submucosal layer. The reduced risk of perforation and bleeding has lead to APC-SSI being available on an outpatient department (OPD) basis without requirement of hospitalization.

We have evaluated the effectiveness of APC-SSI for gastric adenomas with LGD on OPD basis. We conducted a study of 57 patients with a combined total of 64 lesions of gastric adenomas with LGD, including patients who were not suitable for EMR/ESD due to bleeding tendency, serious concomitant disease, poor general condition, and advanced age (Table 1) (Lee, 2009). Gastric adenomas larger than $20 \mathrm{~mm}$, accompanied with surface depression or nodularity, or containing HGD were excluded because of the possibility of co-existing cancerous tissue.

The argon gas flow rate was $2.0 \mathrm{~L} / \mathrm{min}$, and the electrical current was set at $60 \mathrm{~W}$. APC treatment was performed under sedation with midazolam and propofol. After spraying indigocarmine solution onto the lesion, the area around the lesion was marked using an APC probe. Normal saline solution was injected into the submucosal layer under the lesion with a standard disposable $25-\mathrm{G}$ injection needle. Sometimes, indigocarmine solution would be mixed with normal saline for better identification of the submucosal layer. Normal saline-mixed solution was injected until sufficient submucosal swelling was achieved. The lesion and neighboring mucosa inside the marked sites were evenly treated with APC until the lesion was completely coagulated and appeared dry under endoscopic examination (Fig. 6). 


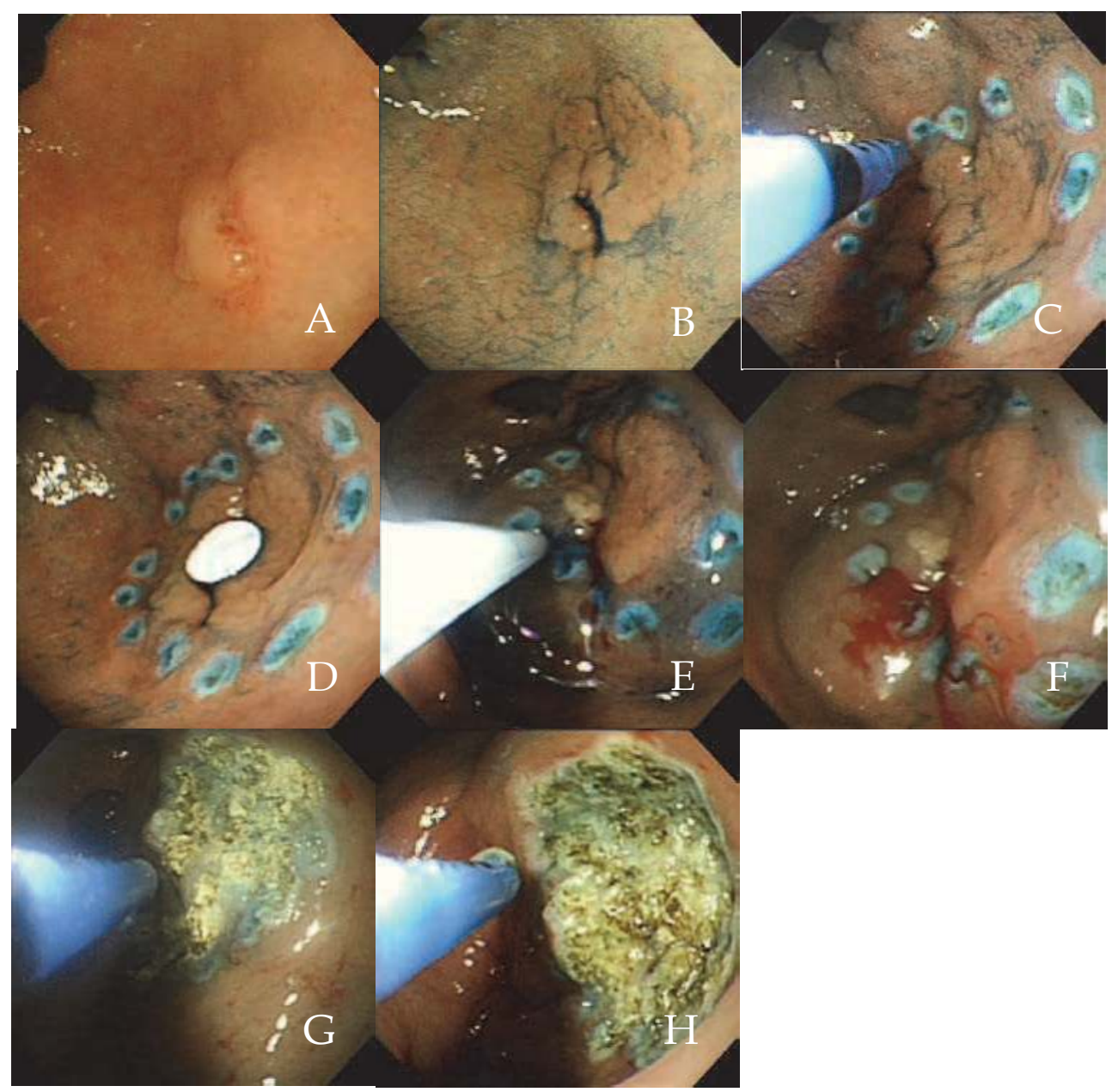

Fig. 6. Endoscopic view of APC-SSI. A) Whitish discolored, flat surfaced, and slightly elevated lesion is noted at the greater curvature side of the distal antrum. B) After indigocarmine solution spraying, the boundary of the lesion is clearly distinct and a granular surface is visible. C) Surrounding markings were done with an APC probe with sufficient distance from the lesion. D) The size of lesion was measured by comparative ratio with $6 \mathrm{~mm}$ sized round piece of vinyl. E) Normal saline or sometimes normal saline-indigocarmine mixture solution was injected to the submucosal layer under the lesion with a standard 25-G injection needle. F) Normal saline solution was injected until sufficient submucosal swelling was achieved. G, H) The lesion and neighboring mucosa inside the marked sites were evenly coagulated with APC until the lesion was completely coagulated and appeared dry under endoscopic examination.

After APC-SSI treatment, patients were closely observed. If there was no specific complaint, patients were discharged from hospital with proton pump inhibitor. On the occasion of severe pain or discomfort, patients were admitted to hospital. After discharge, follow- up endoscopic examinations with forceps biopsy was performed at 3, 6, and 12 months and then every 12 
months. Lesions found at the same site as the previous lesion were defined as being residual. On the other hand, lesions found at a different site were considered to be metachronous. The treatment outcomes of all patients are shown in Table 1 and $93.7 \%$ of gastric adenomas were eradicated with APC-SSI. Four residual lesions (6.3\%) were found at previous treated sites and they were gastric adenomas with LGD during mean follow-up time of $5.8 \pm 3.2$ months (range 3-9 months) (Table 2). Three of these were located at the posterior wall of the upper and mid body. One lesion was located in the prepylorus. The initial lesions were incompletely coagulated probably because their locations were difficult to be accessed with an endoscope.

For instance, the prepyloric lesion extending through the pyloric channel into the mucosa of the duodenal side was incompletely treated with APC probably due to the limitation of endoscopic visual field (Fig. 7). All of the residual adenomas were eradicated with additional APC-SSI treatment and did not reappear during follow-up.

Gender (men-women)

Mean age, yr

Macroscopic type

Patients with concomitant diseases

Patients who refused hospitalization for EMR and with a risk of perforation or bleeding
$45 / 12$

$59.5 \pm 10.9(34-81)$

Flat elevated type 58

Central depressed type 6

32 (56.1\%) (COPD, 8; liver cirrhosis, 6; heart failure, 5 ; renal failure on hemodialysis or peritoneal dialysis, 4 ; others, 9)

$25(43.8 \%)$

EMR, Endoscopic mucosal resection

Table 1. Characteristics of 57 patients with a combined total of 64 lesions of gastric adenoma treated with APC-SSI

\begin{tabular}{|c|c|c|c|c|c|}
\hline $\begin{array}{c}\text { Patient } \\
\text { No. }\end{array}$ & $\begin{array}{l}\text { Age, } \\
\text { yr }\end{array}$ & Gender & Location & $\begin{array}{l}\text { Pathologic } \\
\text { type }\end{array}$ & $\begin{array}{l}\text { Further } \\
\text { treatment }\end{array}$ \\
\hline
\end{tabular}

\begin{tabular}{llllll}
\hline 1 & 66 & $\mathrm{M}$ & $\mathrm{P} / \mathrm{W}$ of Upper body & Adenoma c LGD & APC-SSI \\
2 & 56 & $\mathrm{M}$ & $\mathrm{P} / \mathrm{W}$ of Upper body & Adenoma c LGD & APC-SSI \\
3 & 70 & $\mathrm{M}$ & $\mathrm{P} / \mathrm{W}$ of Mid body & Adenoma c LGD & APC-SSI \\
4 & 59 & $\mathrm{M}$ & G/C of Prepylorus & Adenoma c LGD & APC-SSI \\
\hline
\end{tabular}

P/W, Posterior wall; G/C, Greater curvature; LGD, Low grade dysplasia; APC-SSI, Argon plasma coagulation with submucosal saline injection

Table 2. Characteristics of 4 patients with residual adenoma 


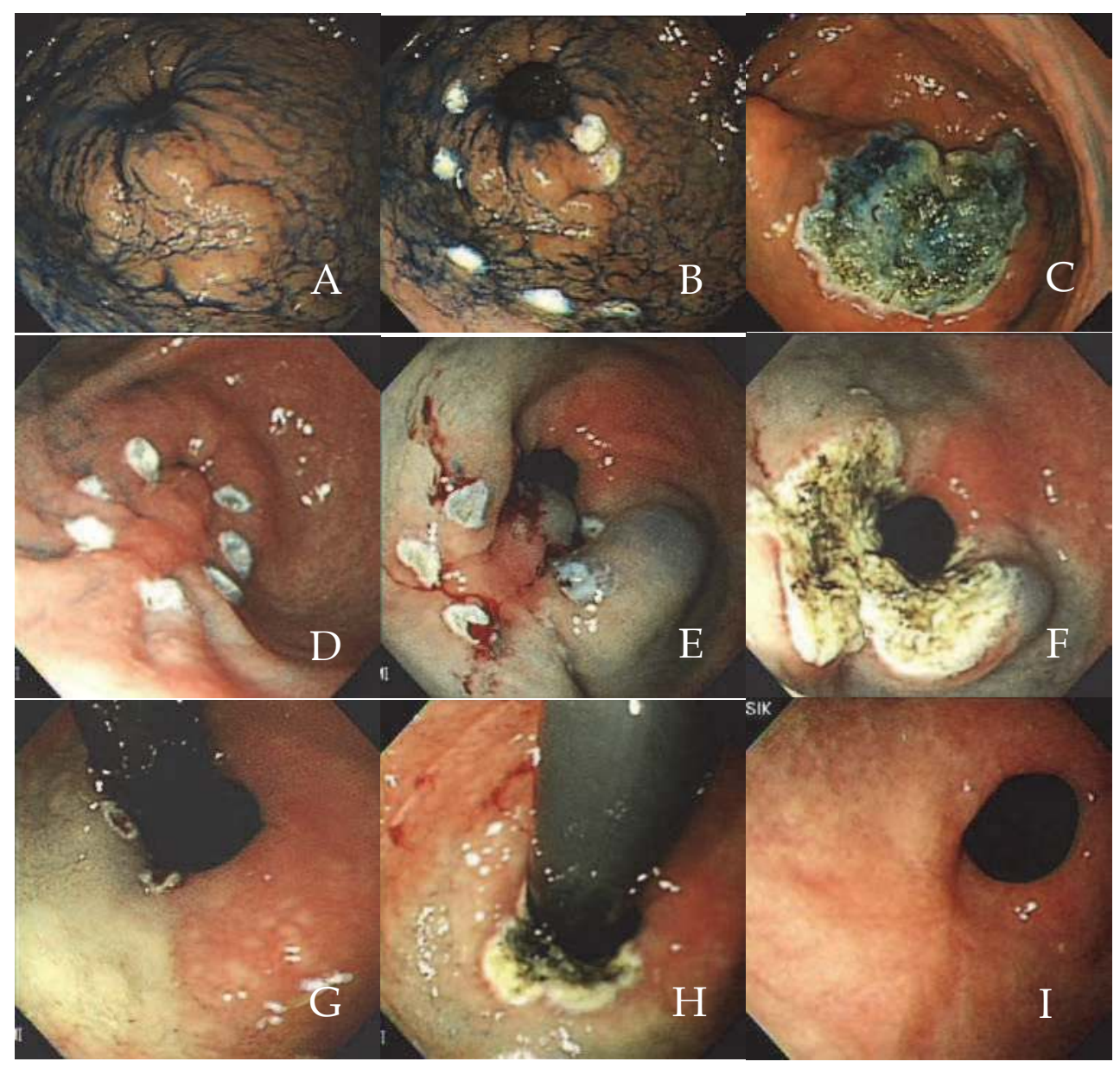

Fig. 7. A case of treatment failure. Residual tumor was found 6 months after APC-SSI for prepyloric lesion. A) Round flat elevated lesion was located at greater curvature side of the distal antrum and prepylorus and has relatively clear margin. B, C) After marking with APC and submucosal saline injection, the lesion and surrounding mucosa was evenly coagulated. D) Follow-up endoscopy at 6 months after APC-SSI, a nodular surfaced elevated mass lesion with fold change was noted. Pathologic examination of biopsy specimen revealed gastric adenoma with LGD. E, F) After marking procedure and submucosal saline injection, the remnant lesion on the antrum was eradicated with APC treatment. G, H) With retroflexion of the endoscope, the lesion had extended into the duodenal bulb. After marking procedure and submucosal saline injection, the remnant lesion on the duodenal side was eradicated with additional APC treatment with retroflexion in the bulb. I) Follow-up endoscopy 1yr after additional treatment revealed healing ulcer scar without tumor recurrence. 


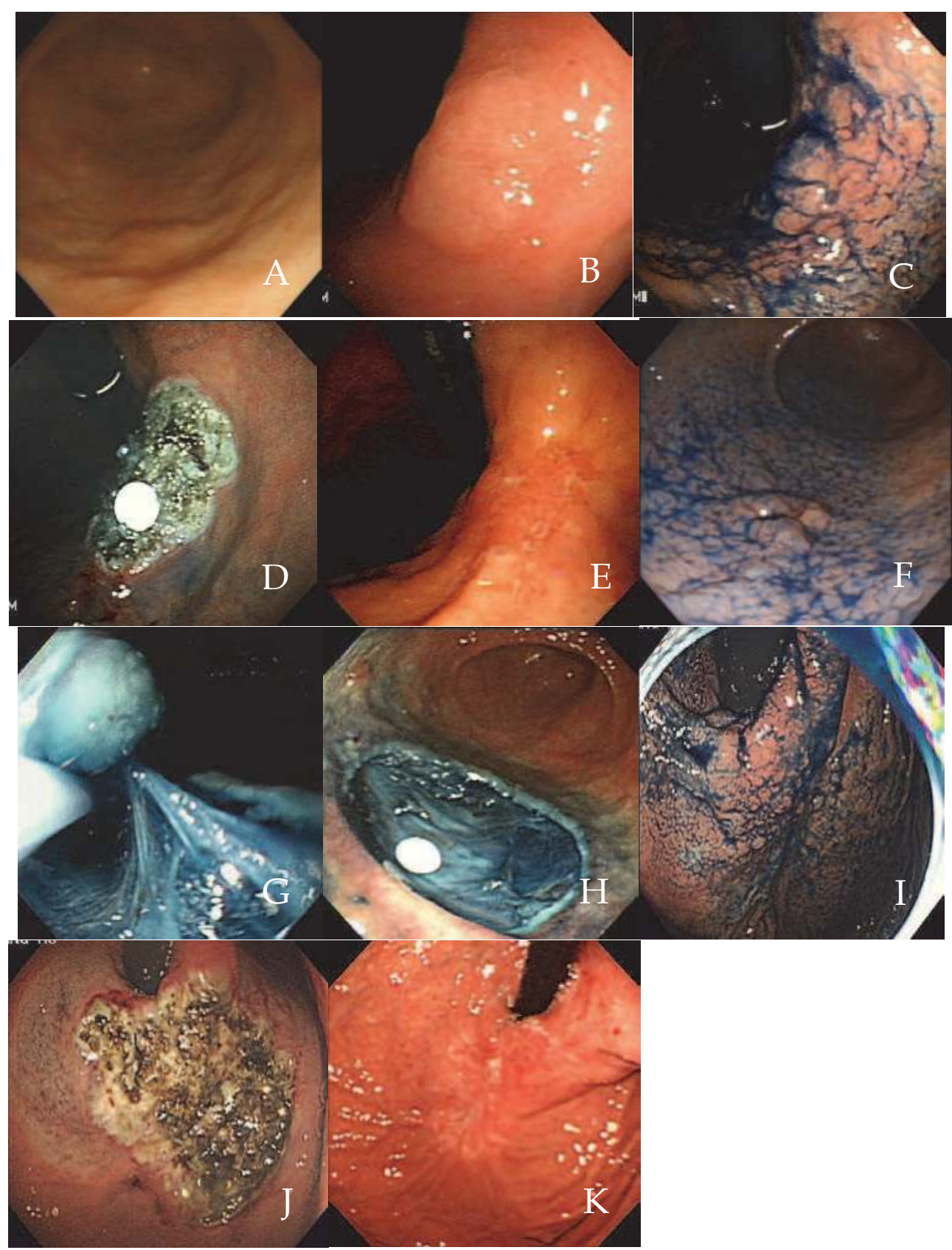

Fig. 8. The case of metachronous intramucosal adenocarcinoma and gastric adenoma after APC-SSI. A) A slightly elevated lesion with smooth surface was noted at the greater 
curvature side of the mid antrum. Endoscopic biopsy revealed Helicobacter gastritis. B) Whitish discolored, flat elevated lesion with clear margin was noted at the lesser curvature side of the gastric angle. C) After indigocarmine spraying, its surface revealed a lobular appearance. D) About $25 \times 24 \mathrm{~mm}$ sized APC-induced round ulceration was noted at the lesser curvature side of the gastric angle. The ulcer base was blue-colored due to the submucosa injection of indigocarmine mixed saline. E) Endoscopic finding at 6 months after APC-SSI showed scarring ulceration with reddish regenerative epithelium.

F) Endoscopic findings at 12 months showed a small elevated lesion with nodular surface at the greater curvature side of the antrum. Forceps biopsy results revealed intramucosal adenocarcinoma.G) For the treatment of the lesion, ESD was done. H) A large ESD-induced ulcer was seen without bleeding or perforation. I) A metachronous flat elevated round lesion was found at the lesser curvature side of the cardia during a follow-up endoscopy 2 years later. Forceps biopsy results revealed it was a gastric adenoma with LGD. J) Based on patient age and tumor location, APC-SSI was successfully done to treat the lesion. K) Endoscopic finding at 6 months after the second APC-SSI showed an ulcer scar. There was no evidence of residual tumor with endoscopic biopsy.

Fourteen metachronous lesions were found in eight patients $(14.0 \%)$ during follow-up (Table 3). Twelve lesions of gastric adenomas with LGD were treated with additional APC-SSI. One lesion of gastric adenoma with HGD was treated with ESD and it was proven to be intramucosal adenocarcinoma (Fig. 8). The other one with intramucosal adenocarcinoma was treated with APC-SSI because of poor general condition and bleeding tendency. Mean interval from treatment to detection of metachronous lesion was $18.1 \pm 11.6$ months.

Mean procedure time for APC-SSI was 15.0 \pm 5.0 (8-30) min. Transient abdominal discomfort occurred in 11 patients. Three complications (4.7\%), including Mallory-Weiss tearing, pneumoperitoneum, and delayed bleeding, were noted (Table 4). Mallory-Weiss tearing was successfully controlled using endoscopic hemoclippings. Pneumoperitoneum occurred in a patient with two broad lesions at the lesser curvature side of the mid and upper body after a longer duration of APC-SSI. Endoscopy the next day showed broad ulcerative lesions with a coagulated base without evidence of perforation. The patient was hospitalized and discharged after 2 days of conservative care. Several authors reported one case each of APCinduced pneumoperitoneum after treatment of acute hemorrhagic radiation proctitis (Chung, 2005; Hoyer, 1998; Manes, 2007). Pneumoperitoneum, however, does not necessarily mean perforation. It can be caused by air leakage through a partially coagulated wall by elevated intraluminal pressure. In our study, argon gas flow rate was $2 \mathrm{~L} / \mathrm{min}$. The long procedure time of APC inevitably induced marked stomach distention and increased intragastric pressure, probably resulting in air leaking into the peritoneal cavity without a visible perforation site of the gastric wall. Delayed bleeding from the regenerative vessels on the APC-induced ulcer occurred in one patient 2 weeks after the procedure and it was successfully managed with additional APC. APC is an effective noncontact technique for bleeding control (Islam, 2009; Grund, 1994; Grund, 1997) and there was no procedurerelated bleeding during and immediately after APC-SSI. This delayed bleeding was not caused by the APC procedure itself but by the healing and regenerative process, indicating that APC may be a safe treatment of gastric adenoma in patients with bleeding risk. This can also bring about stressful retching and Mallory-Weiss tearing. Therefore, frequent suction of 
intragastric gas during procedure is helpful for the prevention of marked gastric distention and barotraumas.

\begin{tabular}{lllcll}
\hline $\begin{array}{l}\text { Patient } \\
\text { No }\end{array}$ & Age & Gender & Time(mon) & Pathologic type & Further treatment \\
\hline 1 & 51 & M & 9 & Adenoma c LGD & APC-SSI \\
2 & 78 & M & 6 & Adenoma c LGD & APC-SSI \\
3 & 49 & M & 12 & Adenoma c LGD & APC-SSI \\
4 & 66 & M & 30 & Intramucosal cancer & APC-SSI \\
5 & 59 & F & 5 & Adenoma c LGD & APC-SSI \\
& & & 19 & Adenoma c LGD & APC-SSI \\
6 & 50 & M & 6 & Adenoma c LGD & APC-SSI \\
& & & 20 & Adenoma c LGD & APC-SSI \\
7 & 51 & M & 12 & Intramucosal cancer & ESD \\
8 & 49 & M & 43 & Adenoma c LGD & APC-SSI \\
& & & 12 & Adenoma c LGD & APC-SSI \\
& & & 19 & Adenoma c LGD & APC-SSI \\
& & & 28 & Adenoma c LGD & APC-SSI \\
\hline
\end{tabular}

P/W, Posterior wall; G/C, Greater curvature; LGD. Low grade dysplasia; APC-SSI, Argon plasma coagulation with submucosal saline injection; ESD, Endoscopic submucosal dissection

Table 3. Characteristics of 14 metachronous lesions of 8 patients

\begin{tabular}{ll}
\hline Mean duration of follow-up (mo) & $19.5 \pm 15.1(6-49)$ \\
Mean time required for treatment (min) & $15.0 \pm 5.0$ \\
Patients with complications & $3(4.7 \%)$ \\
Mallory Weiss tearing & 1 \\
Pneumoperitoneum & 1 \\
Delayed bleeding & 1 \\
Patients with residual adenoma & $4(7.0 \%)$ \\
Patients with metachronous adenoma & $8(14.0 \%)$ \\
\hline
\end{tabular}

Table 4. Outcomes of endoscopic argon plasma coagulation with submucosal saline injection treatment $(\mathrm{n}=64)$

There are two important viewpoints in this study. One is the importance of the accurate identification of the lateral margin of the lesion. Because gastric adenomas are confined to 
the mucosal layer and the entire lesion can be ablated with APC, residual lesions may be left near the lateral margin but away from the deep layer (Morson, 1980, Rugge, 1995). Lesion marking should include a sufficient amount of normal tissue around the lesion to ensure a successful APC-SSI, preventing treatment failure, as seen in EMR or ESD. Unlike colorectal or esophageal lesions whose margins are rather easy to delineate with indigocarmine or Lugol spraying, the margins of gastric tumors are sometimes difficult to diagnose, because the background mucosa is affected by acute or chronic inflammation or intestinal metaplasia. Because indigocarmine accumulates in the grooves and emphasizes the surface structural changes of the mucosa, it is difficult to identify the margin of the lesion which surface change is not distinct. Therefore, it could result in incomplete resection with positive lateral margin in EMR or ESD, and also leave residual tissue in those who receive APC treatment for adenomas. Inability to perform histopathologic evaluation of resected specimen is a shortcoming of APC treatment of gastric adenomas and we recommend sufficient margin to be obtained before APC-SSI for the prevention of residual tissue. Therefore, endoscopists should pay more attention to the lesions at difficult sites for endoscopic approach, such as the posterior wall of the upper and mid body, making sure there is sufficient margin from the lesions.

The other viewpoint is the high prevalence of metachronous lesions after APC-SSI for gastric adenomas. We found 14 metachronous lesions in eight patients, and their locations were different from their original lesions during a mean of 19.5 months of follow-up. Those who have risk factors of gastric adenomas, including chronic atrophic gastritis, intestinal metaplasia, Helicobacter pylori infection, old age, cigarette smoking, and alcohol drinking, are more likely to develop metachronous lesions even after APC treatment. Chronic atrophic gastritis and intestinal metaplasia are known to be irreversible and may work as a continuous background of gastric cancer to recur at other sites (Talley, 1991; Parsonnet, 1991; Nomura, 1991). Because patients who have risk factors of gastric adenomas have an increased risk of metachronous lesions, meticulous endoscopic followup should be done after the treatment of gastric adenomas (Talley, 1991; Parsonnet, 1991; Nomura, 1991).

\section{Conclusion}

Gastric adenomas are well-known as premalignant lesions of gastric cancer. Gastric adenomas with LGD show a relatively benign natural course and low risk of progression, compared with gastric adenomas with HGD. Though endoscopic resection has become the standard treatment of intramucosal carcinomas and adenomas with HGD, there is controversy about the therapeutic option of gastric adenomas with LGD. APC-SSI is the most reasonable and feasible treatment being safe and effective, which can be done in place of endoscopic resection and repeated endoscopic follow-up.

\section{References}

Asaka, M. (1997). What role does Helicobacter pylori play in gastric cancer? Gastroenterology, Vol.113, No. 6 Suppl, (September 1996), pp S56-60, ISSN 00165085 
Bearzi, I. (1994). Gastric dysplasia: a ten-year follow-up study. Pathol Res Pract, Vol.190, No. 1, (August 1993), pp 61-68, ISSN 0344-0338

Chau, C H. (2003). Randomized controlled trial comparing epinephrine injection plus heat probe coagulation versus epinephrine injection plus argon plasma coagulation for bleeding peptic ulcers. Gastrointest Endosc, Vol.57, No. 4, (May 2002), pp 455-461, ISSN 0016-5107

Chung, Y F and W H Koo. (2005). Gastric pneumatosis after endoscopic argon plasma coagulation. Ann Acad Med Singapore, Vol.34, No. 9, (April 2001), pp 569-570, ISSN 0304-4602

Cipolletta, L. (1998). Prospective comparison of argon plasma coagulator and heater probe in the endoscopic treatment of major peptic ulcer bleeding. Gastrointest Endosc, Vol.48, No. 2, (July 1997), pp 191-195, ISSN 0016-5107

Di Gregorio, C. (1993). Gastric dysplasia. A follow-up study. Am J Gastroenterol, Vol.88, No. 10, (January 1993), pp 1714-1719, ISSN 0002-9270

Ell, C. (1998). Photodynamic ablation of early cancers of the stomach by means of mTHPC and laser irradiation: preliminary clinical experience. Gut, Vol.43, No. 3, (October 1997), pp 345-349, ISSN 0017-5749

Farinati, F. (1993). Early and advanced gastric cancer in the follow-up of moderate and severe gastric dysplasia patients. A prospective study. I.G.G.E.D.--Interdisciplinary Group on Gastric Epithelial Dysplasia. Endoscopy, Vol.25, No. 4, (December 1992), pp 261-264, ISSN 0013-726X

Fertitta, A M. (1993). Clinical significance of gastric dysplasia: a multicenter follow-up study. Gastrointestinal Endoscopic Pathology Study Group. Endoscopy, Vol.25, No. 4, (March 1992), pp 265-268, ISSN 0013-726X

Fertitta, A M. (1993). Clinical significance of gastric dysplasia: a multicenter follow-up study. Gastrointestinal Endoscopic Pathology Study Group. Endoscopy, Vol.25, No. 4, (May 1992), pp 265-268, ISSN 0013-726X

Fujishiro, M. (2004). Comparison of various submucosal injection solutions for maintaining mucosal elevation during endoscopic mucosal resection. Endoscopy, Vol.36, No. 7, (June 2003), pp 579-583, ISSN 0013-726X

Fujishiro, M. (2006). Submucosal injection of normal saline may prevent tissue damage from argon plasma coagulation: an experimental study using resected porcine esophagus, stomach, and colon. Surg Laparosc Endosc Percutan Tech, Vol.16, No. 5, (August 2005), pp 307-311, ISSN 1530-4515

Fujishiro, M. (2008). Submucosal Injection of Normal Saline can Prevent Unexpected Deep Thermal Injury of Argon Plasma Coagulation in the in vivo Porcine Stomach. Gut Liver, Vol.2, No. 2, (January 2008), pp 95-98, ISSN 1976-2283

Giovannini, M. (1999). Endoscopic mucosal resection (EMR): results and prognostic factors in 21 patients. Endoscopy, Vol.31, No. 9, (June 1999), pp 698-701, ISSN 0013726X

Goulet, C J. (2007). In vivo evaluation of argon plasma coagulation in a porcine model. Gastrointest Endosc, Vol.65, No. 3, (May 2006), pp 457-462, ISSN 00165107 
Grund, K E. (1994). Endoscopic argon plasma coagulation (APC) first clinical experiences in flexible endoscopy. Endosc Surg Allied Technol, Vol.2, No. 1, (April 1993), pp 4246, ISSN 0942-6027

Grund, K E. (1997). [Argon plasma coagulation through a flexible endoscope. Evaluation of a new therapeutic method after 1606 uses]. Dtsch Med Wochenschr, Vol.122, No. 14, (March 1997), pp 432-438, ISSN 0012-0472 21.

Hiki, Y. (1989). The concepts, procedures, and problems related in endoscopic laser therapy of early gastric cancer. A retrospective study on early gastric cancer. Surg Endosc, Vol.3, No. 1, (September 1988), pp 1-6, ISSN 0930-2794

Hoyer, N. (1998). Massive pneumoperitoneum after endoscopic argon plasma coagulation. Endoscopy, Vol.30, No. 3, (November 1997), pp S44-45, ISSN 0013-726X

Iacopini, F. (2007). Hemostasis of Dieulafoy's lesions by argon plasma coagulation (with video). Gastrointest Endosc, Vol.66, No. 1, (June 2006), pp 20-26, ISSN 00165107

Imaoka, W. (1987). Is curative endoscopic treatment of early gastric cancer possible? Endoscopy, Vol.19 Suppl 1, No., (July 1986), pp 7-11, ISSN 0013-726X

Islam, S and K K Tan. (2009). Bleeding inflammatory polyp formation as a complication of argon plasma coagulation therapy on a flat gastric angiodysplasia. Endoscopy, Vol.41 Suppl 2, No., (July 2008), pp E86, ISSN 1438-8812

Kaassis, M. (2000). Argon plasma coagulation for the treatment of hemorrhagic radiation proctitis. Endoscopy, Vol.32, No. 9, (October 1999), pp 673-676, ISSN 0013-726X

Kamiya, T. (1982). Long-term follow-up study on gastric adenoma and its relation to gastric protruded carcinoma. Cancer, Vol.50, No. 11, (January 1982), pp 2496-2503, ISSN 0008-543X

Kitamura, T. (2006). Argon plasma coagulation for early gastric cancer: technique and outcome. Gastrointest Endosc, Vol.63, No. 1, (September 2005), pp 48-54, ISSN 0016-5107

Kwan, V. (2006). Argon plasma coagulation in the management of symptomatic gastrointestinal vascular lesions: experience in 100 consecutive patients with longterm follow-up. Am J Gastroenterol, Vol.101, No. 1, (June 2005), pp 58-63, ISSN 0002-9270

Lansdown, M. (1990). High grade dysplasia of the gastric mucosa: a marker for gastric carcinoma. Gut, Vol.31, No. 9, (April 1989), pp 977-983, ISSN 0017-5749

Lee, K M. (2009). Argon plasma coagulation with submucosal saline injection for gastric adenoma on outpatient basis. Dig Dis Sci, Vol.54, No. 12, (March 2008), pp 26232628, ISSN 1573-2568

Manes, G. (2007). Pneumoperitoneum after argon plasma coagulation treatment: perforation or accumulation of air in the cavity? Endoscopy, Vol.39 Suppl 1, No., (April 2006), pp E98, ISSN 1438-8812

Mimura, S. (1996). Cooperative clinical trial of photodynamic therapy with photofrin II and excimer dye laser for early gastric cancer. Lasers Surg Med, Vol.19, No. 2, (May 1995), pp 168-172, ISSN 0196-8092 
Miyata, M. (2000). What are the appropriate indications for endoscopic mucosal resection for early gastric cancer? Analysis of 256 endoscopically resected lesions. Endoscopy, Vol.32, No. 10, (June 1999), pp 773-778, ISSN 0013-726X

Morson, B C. (1980). Precancerous conditions and epithelial dysplasia in the stomach. J Clin Pathol, Vol.33, No. 8, (May 1979), pp 711-721, ISSN 0021-9746

Nakamura, S. (2001). Endoscopic induction of mucosal fibrosis by argon plasma coagulation (APC) for esophageal varices: A prospective randomized trial of ligation plus APC vs. ligation alone. Endoscopy, Vol.33, No. 3, (October 2000), pp 210-215, ISSN 0013726X

Nakamura, T. (1990). Photodynamic therapy for early gastric cancer using a pulsed gold vapor laser. J Clin Laser Med Surg, Vol.8, No. 5, (March 1989), pp 63-67, ISSN 10445471

Nomura, A. (1991). Helicobacter pylori infection and gastric carcinoma among Japanese Americans in Hawaii. N Engl J Med, Vol.325, No. 16, (June 1990), pp 1132-1136, ISSN 0028-4793

Norton, I D. (2002). Efficacy of colonic submucosal saline solution injection for the reduction of iatrogenic thermal injury. Gastrointest Endosc, Vol.56, No. 1, (August 2001), pp 95-99, ISSN 0016-5107

Oka, S. (2006). Advantage of endoscopic submucosal dissection compared with EMR for early gastric cancer. Gastrointest Endosc, Vol.64, No. 6, (October 2005), pp 877-883, ISSN 0016-5107

Oka, S. (2006). Endoscopic submucosal dissection for residual/local recurrence of early gastric cancer after endoscopic mucosal resection. Endoscopy, Vol.38, No. 10, (November 2005), pp 996-1000, ISSN 0013-726X

Olmos, J A. (2006). Long-term outcome of argon plasma ablation therapy for bleeding in 100 consecutive patients with colonic angiodysplasia. Dis Colon Rectum, Vol.49, No. 10, (February 2006), pp 1507-1516, ISSN 0012-3706

O'Mahony, S. (2001). Endoscopic mucosal resection for early gastric cancer. Gut, Vol.48, No. 2, (May 2000), pp 151-152, ISSN 0017-5749

Ono, H. (2001). Endoscopic mucosal resection for treatment of early gastric cancer. Gut, Vol.48, No. 2, (June 2000), pp 225-229, ISSN 0017-5749

Parsonnet, J. (1991). Helicobacter pylori infection and the risk of gastric carcinoma. N Engl J Med, Vol.325, No. 16, (September 1990), pp 1127-1131, ISSN 0028-4793

Postgate, A. (2007). Argon plasma coagulation in chronic radiation proctitis. Endoscopy, Vol.39, No. 4, (November 2006), pp 361-365, ISSN 1438-8812

Prost, B. (2004). Unusual complications of argon plasma coagulation. Gastrointest Endosc, Vol.59, No. 7, (August 2003), pp 929-932, ISSN 0016-5107

Rolachon, A. (2000). Is argon plasma coagulation an efficient treatment for digestive system vascular malformation and radiation proctitis? Gastroenterol Clin Biol, Vol.24, No. 12, (July 1999), pp 1205-1210, ISSN 0399-8320

Rugge, M. (1991). Gastric epithelial dysplasia: a prospective multicenter follow-up study from the Interdisciplinary Group on Gastric Epithelial Dysplasia. Hum Pathol, Vol.22, No. 10, (January 1990), pp 1002-1008, ISSN 0046-8177 
Rugge, M. (1994). Gastric epithelial dysplasia in the natural history of gastric cancer: a multicenter prospective follow-up study. Interdisciplinary Group on Gastric Epithelial Dysplasia. Gastroenterology, Vol.107, No. 5, (March 1993), pp 1288-1296, ISSN 0016-5085

Rugge, M. (1995). Gastric epithelial dysplasia. How clinicopathologic background relates to management. Cancer, Vol.76, No. 3, (April 1994), pp 376-382, ISSN 0008$543 X$

Sagawa, T. (2003). Argon plasma coagulation for successful treatment of early gastric cancer with intramucosal invasion. Gut, Vol.52, No. 3, (June 2002), pp 334-339, ISSN 00175749

Saraga, E P. (1987). Gastric dysplasia. A histological follow-up study. Am J Surg Pathol, Vol.11, No. 10, (April 1986), pp 788-796, ISSN 0147-5185.

Sato, T. (2005). Efficacy of argon plasma coagulation for gastric antral vascular ectasia associated with chronic liver disease. Hepatol Res, Vol.32, No. 2, (May 2004), pp 121-126, ISSN 1386-6346

Sibille, A. (1995). Endoscopic Nd:YAG treatment of superficial gastric carcinoma: experience in 18 Western inoperable patients. Gastrointest Endosc, Vol.42, No. 4, (June 1994), pp 340-345, ISSN 0016-5107 56.

Tabuse, K. (1985). Microwave tissue coagulation applied clinically in endoscopic surgery. Endoscopy, Vol.17, No. 4, (June 1984), pp 139-144, ISSN 0013-726X

Tajiri, H and Y Oguro. (1991). Laser endoscopic treatment for upper gastrointestinal cancers. J Laparoendosc Surg, Vol.1, No. 2, (August 1990), pp 71-78, ISSN 10523901

Takenaka, R. (2008). Risk factors associated with local recurrence of early gastric cancers after endoscopic submucosal dissection. Gastrointest Endosc, Vol.68, No. 5, (March 2007), pp 887-894, ISSN 1097-6779

Takeuchi, Y. (2007). Endoscopic submucosal dissection with insulated-tip knife for large mucosal early gastric cancer: a feasibility study (with videos). Gastrointest Endosc, Vol.66, No. 1, (May 2006), pp 186-193, ISSN 0016-5107

Talley, N J. (1991). Gastric adenocarcinoma and Helicobacter pylori infection. J Natl Cancer Inst, Vol.83, No. 23, (August 1990), pp 1734-1739, ISSN 0027-8874

The EUROGAST study group (1993). An international association between Helicobacter pylori infection and gastric cancer. The EUROGAST Study Group. Lancet, Vol.341, No. 8857, (October 1992), pp 1359-1362, ISSN 0140-6736

Wahab, P J. (1997). Argon plasma coagulation in flexible gastrointestinal endoscopy: pilot experiences. Endoscopy, Vol.29, No. 3, (November 1996), pp 176-181, ISSN 0013$726 \mathrm{X}$

Watanabe, K. (2006). Clinical outcomes of EMR for gastric tumors: historical pilot evaluation between endoscopic submucosal dissection and conventional mucosal resection. Gastrointest Endosc, Vol.63, No. 6, (May 2005), pp 776-782, ISSN 0016-5107

Watson, J P. (2000). The tissue effect of argon plasma coagulation on esophageal and gastric mucosa. Gastrointest Endosc, Vol.52, No. 3, (April 1999), pp 342-345, ISSN 00165107 
Yasuda, K. (1993). Endoscopic laser treatment for early gastric cancer. Endoscopy, Vol.25, No. 7, (December 1992), pp 451-454, ISSN 0013-726X

Yoshida, T. (2005). The clinical meaning of a nonstructural pattern in early gastric cancer on magnifying endoscopy. Gastrointest Endosc, Vol.62, No. 1, (November 2004), pp 48-54, ISSN 0016-5107 


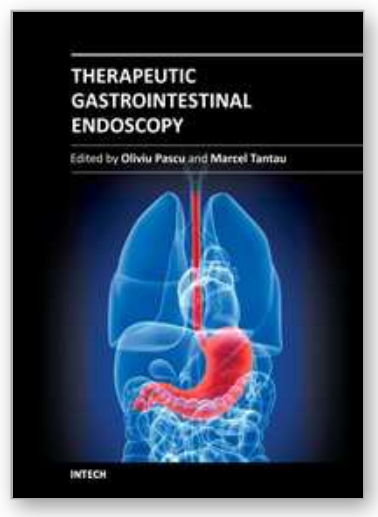

\author{
Therapeutic Gastrointestinal Endoscopy \\ Edited by Prof. Oliviu Pascu
}

ISBN 978-953-307-743-7

Hard cover, 216 pages

Publisher InTech

Published online 22, September, 2011

Published in print edition September, 2011

Endoscopy has had a big role in the development of modern gastroenterology. Modern endoscopy will certainly be more therapeutic. It started with endoscopic hemostasis and polipectomy, than beginning of the 1970 's with the advent of endoscopic sphincterotomy extended to biliopancreatic pathology and has a huge impact in this difficult pathology. Plastic stents made the first steps in endoscopic palliation of neoplastic jaundice, metallic stents, covered or uncovered are better for biliary palliation and can be used also for palliation neoplastic obstruction at different levels of the digestive tube. Resection of digestive tumors has evolved now to sub-mucosal resection, looking to have one-piece complete resection. Interventional endoscopy is now very complex and takes a lot of time for endoscopists to learn properly these techniques. This book is a very good up-to-date overview of new techniques of interventional endoscopy for those who want to learn or develop their knowledges in this field.

\title{
How to reference
}

In order to correctly reference this scholarly work, feel free to copy and paste the following:

Kee Myung Lee and Jin Hong Kim (2011). Endoscopic Treatment of Gastric Adenoma with Argon Plasma Coagulation, Therapeutic Gastrointestinal Endoscopy, Prof. Oliviu Pascu (Ed.), ISBN: 978-953-307-743-7, InTech, Available from: http://www.intechopen.com/books/therapeutic-gastrointestinal-endoscopy/endoscopictreatment-of-gastric-adenoma-with-argon-plasma-coagulation1

\section{INTECH}

open science | open minds

\author{
InTech Europe \\ University Campus STeP Ri \\ Slavka Krautzeka 83/A \\ 51000 Rijeka, Croatia \\ Phone: +385 (51) 770447 \\ Fax: +385 (51) 686166 \\ www.intechopen.com
}

\author{
InTech China \\ Unit 405, Office Block, Hotel Equatorial Shanghai \\ No.65, Yan An Road (West), Shanghai, 200040, China \\ 中国上海市延安西路65号上海国际贵都大饭店办公楼 405 单元 \\ Phone: +86-21-62489820 \\ Fax: $+86-21-62489821$
}


(C) 2011 The Author(s). Licensee IntechOpen. This chapter is distributed under the terms of the Creative Commons Attribution-NonCommercialShareAlike-3.0 License, which permits use, distribution and reproduction for non-commercial purposes, provided the original is properly cited and derivative works building on this content are distributed under the same license. 